\title{
Population genetic structure in a Robertsonian race of house mice: evidence from microsatellite polymorphism
}

\author{
J. F. DALLAS*†, F. BONHOMME†, P. BOURSOT†, J . BRITTON-DAVIDIAN + \& \\ V. BAUCHAU§ \\ †Laboratoire Génome et Populations, CNRS UPR 9060, and łLaboratoire Génétique et Environnement, CNRS UMR \\ 5554, Université Montpellier II, Place Eugène Bataillon, 34095 Montpellier Cedex 5, France and §Netherlands \\ Institute of Ecology, Centre for Terrestrial Ecology, Boterhoeksestraat 22, PO Box 40, 6666 ZG Heteren, The \\ Netherlands
}

\begin{abstract}
Genetic evidence was assessed for inbreeding and population subdivision in a Robertsonian fusion $(\mathrm{Rb})$ race of the western European form of house mouse, Mus musculus domesticus, in central Belgium. Inbreeding, and the factors responsible for subdivision (genetic drift and extinction-recolonization) can theoretically influence the fixation of underdominant $\mathrm{Rb}$ variants. The data consisted of allele frequencies of eight microsatellite loci and of the $\mathrm{Rb}(4.12)$ and $\mathrm{Rb}(5.10)$ chromosomes. Six populations were sampled once, and a seventh was sampled successively over 3 years. No evidence for inbreeding within populations was found. Levels of between-population subdivision were high $(\theta=0.15-0.39)$, and showed no association with either karyotype or geographical distance over $8-60 \mathrm{~km}$. In addition, low values of effective size were found in the successively sampled population $\left(N_{\mathrm{e}}=5-20\right)$. Cases of significant two-locus disequilibria were associated with the most closely linked pair of microsatellite loci $(r=0.15)$ : also consistent with small effective sizes. These results suggest that both the lack of inbreeding, and the combined effects of genetic drift and extinction-recolonization, may promote $\mathrm{Rb}$ polymorphism in $M$. m. domesticus.
\end{abstract}

Keywords: drift, extinction-recolonization, inbreeding, Mus, subdivision.

\section{Introduction}

Robertsonian $(\mathrm{Rb})$ fusion chromosomes are often assumed to be underdominant because of meiotic nondisjunction in $\mathrm{Rb}$ heterozygotes (Gropp \& Winking, 1981). Theoretical studies suggest that such polymorphisms can, nonetheless, be fixed in local populations by a variety of factors acting singly or in combination. The finding of chromosomal differences between many closely related species suggests that the fixation of chromosomal variants occurs frequently in evolution. In the case of strict underdominance (equal fitness of both homozygotes and reduced heterozygote fitness), an unstable equilibrium frequency exists below which the mutant is eliminated and above which it progresses to fixation

*Correspondence and present address: Department of Zoology, University of Aberdeen, Tillydrone Avenue, Aberdeen AB24 2TZ, U.K. E-mail: j.dallas@abdn.ac.uk
(Wright, 1941). Any factor which causes the frequency of underdominants to fluctuate above the equilibrium can thus promote fixation. Genetic drift and extinction-recolonization events are two such factors (Hedrick, 1981; Lande, 1985). Under extinction-recolonization, the probability of fixation in semi-isolated demes is maximized at intermediate rates of gene flow (Michalakis \& Olivieri, 1993). Two other relevant factors are inbreeding, which slows down the progress to fixation under genetic drift, and meiotic drive, which either lowers or eliminates the equilibrium frequency (Hedrick, 1981). Such theoretical considerations apply mainly to subdivided populations because in large, continuous populations fixation is likely only when the mutant homozygote has a substantial selective advantage (Barton \& Rouhani, 1991). In this study genetic data were analysed to determine whether the usual structure of house mouse populations displaying $\mathrm{Rb}$ poly- 
morphism is influenced by inbreeding and the combined effects of genetic drift and extinctionrecolonization.

The western European form of the house mouse, Mus musculus domesticus Rutty, contains many chromosomal races possessing varying numbers of Robertsonian fusion $(\mathrm{Rb})$ chromosomes (Boursot $e t$ al., 1993). Such races occur as localized patches (e.g. Hauffe \& Searle, 1993) most of which have arisen independently (Nachman et al., 1994). In contrast, the eastern form, M. m. musculus, displays little $\mathrm{Rb}$ polymorphism. It has been suggested that population-level factors such as inbreeding and genetic drift cannot be responsible for such widespread $\mathrm{Rb}$ polymorphism in $M$. m. domesticus because population genetic structure is very similar in both forms (Nachman \& Searle, 1995). In fact, the paucity of studies involving both forms of house mouse makes this conclusion premature.

This study concerns a well-characterized $\mathrm{Rb}$ race of commensal M. m.domesticus in central Belgium (Bauchau et al., 1990). The race is defined by the presence of two $\mathrm{Rb}$ chromosomes. $\mathrm{Rb}(4.12)$ occurs in a roughly circular area of $7900 \mathrm{~km}^{2}$, and is fixed in some central populations. $\mathrm{Rb}(5.10)$ has a much smaller distribution centred within that of $\mathrm{Rb}(4.12)$, and is segregating in all populations examined. This race may be expanding because it has no obvious geographical constraints, and because the clines of the different $\mathrm{Rb}$ chromosomes are not coincident.

Frequency data on microsatellite and $\mathrm{Rb}$ polymorphisms in samples from seven sites from $\mathrm{Rb}$ populations and from standard $(2 n=40)$ populations from surrounding areas were used to determine whether local populations were random mating or inbred, and to estimate levels of genetic subdivision between populations. Levels of genetic subdivision in central Belgium were compared to those found in the western and eastern European forms of house mice, M.m.domesticus and M. m. musculus, from Jutland (Dallas et al., 1995). Lastly, two aspects of population genetic structure which are indicators of small population sizes were studied: variance effective sizes in one population, and the extent of two-locus disequilibrium in all populations.

The relationship between genetic subdivision and geographical distance was studied using microsatellite data because genetic subdivision for neutral markers is either reduced or eliminated within areas of high gene flow. The form of this relationship was used to differentiate between two migration models for house mice. These models follow from the ecological and behavioural evidence which suggests that both passive (via human transport) and active dispersal occur (Boursot et al., 1993). If passive dispersal occurs sufficiently often throughout a given area, this situation would correspond to the island model in which migration rate does not depend on the distance between subpopulations. Alternatively, if most migration is active, or if passive migration occurs infrequently and over short distances, this situation would favour the stepping-stone model, in which migration occurs only between adjacent subpopulations. This is because mouse habitat is patchy rather than continuous, and because intuition suggests that their ability to travel actively long distances between patches is limited.

Microsatellite polymorphism may contain more signal, and more noise, about population subdivision than other nuclear markers, such as allozymes or restriction fragment length polymorphisms. This is because the sizes of existing microsatellite alleles contain information about prior sizes in the two-phase model proposed for microsatellite mutation (DiRienzo et al., 1994). In this study, subdivision was estimated using two statistics: $R_{\mathrm{ST}}$, which incorporates such mutational memory (Slatkin, 1995), and $\theta$ (Weir \& Cockerham, 1984), which, being based on the infinite alleles model of mutation, has no memory.

\section{Materials and methods}

Twelve samples of commensal M.m.domesticus, each consisting of 10-63 individuals, were collected at seven sites in central Belgium between November 1988 and May 1992. The sites were named after the nearest village; two sites nearest the same village were lettered, and successive samples from the same site, were numbered. Four sites were located in the area where the $\mathrm{Rb}(4.12)$ and $\mathrm{Rb}(5.10)$ chromosomes occur (La Hulpe, Chastre, Monstrieux and Corroy), and three sites were located in an area to the southeast containing only mice of standard karyotype (Spontin a, Spontin b, and Space; Fig. 1). One site, La Hulpe, was sampled six times over a 3-year period (samples LH1-6), and the other sites were sampled once. Mice were live-trapped inside buildings and killed in the laboratory for chromosomal and molecular analyses. The mean sampling period was 24 days (range 2-76). Distances between sites were calculated as straight-line measurements on 1:20,000 maps. Total cellular DNA was extracted from frozen tails as described previously (Dallas et $a l ., 1995)$. Individual karyotypes were prepared from bone marrow or blood culture, and G-banding was performed according to Evans (1987). The presence 


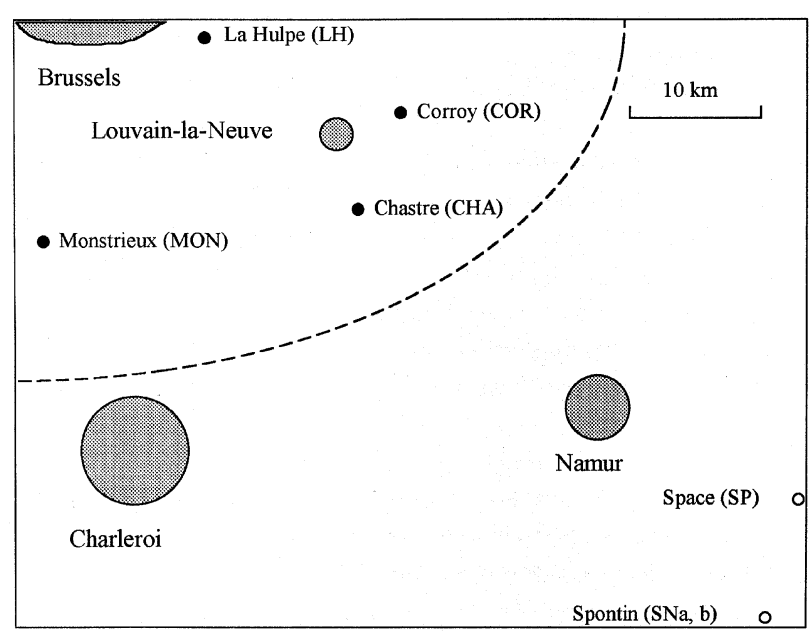

Fig. 1 Locations of house mouse sample sites. Small black circles, sites where $\mathrm{Rb}(4.12)$ and $\mathrm{Rb}(5.10)$ occur; small empty circles, standard karyotype; large grey circles, major cities. The dotted line shows the approximate limit of the $\mathrm{Rb}(4.12)$ distribution.

of the Robertsonian fusions, $\mathrm{Rb}(4.12)$ in all the samples, and of $\mathrm{Rb}(5.10)$ in eight of the samples, was scored by light microscopy.

Eight microsatellites with three, four or five basepair motifs were employed; four $(34,105,135$ and 150) from Hearne et al. (1991), and four (D7Mit18, D11Mit16, D13Mit14, D15Mit16) from Dietrich et al. (1992). Information on motif sizes was provided by Research Genetics, Inc. Microsatellites were amplified by PCR, resolved by nondenaturing polyacrylamide gel electrophoresis (PAGE), and visualized by ethidium bromide staining. Allelic differences of one motif could be resolved, and alleles distinguished from heteroduplex patterns. Alleles of 34, 105, 135, 150 and D15Mit16 were numbered using as standards those identified in a previous study of house mice in Jutland (Dallas et al., 1995). Alleles of D7Mit18, D11Mit16 and D13Mit14 were identified using as standards alleles previously sized in mouse inbred strains (Dietrich et al., 1992), and alleles tentatively identified in the first samples analysed. For D11Mit16, the published allele sizes of inbred strains $\mathrm{A} / \mathrm{J}$ and $\mathrm{AKR} / \mathrm{J}$ are inverted as compared to those found (and checked) here. Alleles of D7Mit18 were numbered from the smallest: 1-4, 7-11; putative alleles 5 and 6 of D7Mit18 were not observed. Alleles of D11Mit16 and D13Mit14 were numbered consecutively from 1, the smallest.

Allele frequencies and unbiased heterozygosity averaged over microsatellite loci were calculated for each sample using BIOSYs-1. Hardy-Weinberg and two-locus disequilibria within samples were identified using GENEPOP 1.2 (Raymond \& Rousset, 1995). Wright's $F$-statistics were estimated according to Weir \& Cockerham (1984) using a modified version of DIPLOID (Weir, 1990; J. Goudet, personal communication). This package estimates $F_{\text {IS }}$ as $f, F_{\text {IT }}$ as $F, F_{\mathrm{ST}}$ as $\theta$, and calculates confidence intervals of $f, F$ and $\theta$ by performing 1000 bootstrap resamples of the single-locus estimates.

Slatkin's $R_{\mathrm{ST}}$ was calculated for each microsatellite locus as Excoffier's $\Phi_{\mathrm{ST}}$ using AMOva 1.55 (L. Excoffier, personal communication), the two statistics being equivalent (Michalakis \& Excoffier, 1996). In AMOVA, $\Phi_{\mathrm{ST}}$ is estimated for one locus as:

$\Phi_{\mathrm{ST}}=\mathrm{V}(A) /[\mathrm{V}(A)+\mathrm{V}(B)]$,

where $\mathrm{V}(A)$ is the between-sample variance in allele size, and $\mathrm{V}(B)$ is the within-sample variance in allele size. Multilocus values of $R_{\mathrm{ST}}$ were calculated by averaging the single-locus values of $\mathrm{V}(A)$ and $\mathrm{V}(B)$, then calculating the above ratio as:

$R_{\mathrm{ST}}=\overline{\mathrm{V}(A)} /[\overline{\mathrm{V}(A)}+\overline{\mathrm{V}(B)}]$.

A Genstat 5.3.1 program was used to generate 95 per cent confidence intervals for multilocus $R_{\mathrm{ST}}$ values, as follows. One thousand bootstrap resamples of single-locus pairs of values, $\mathrm{V}(A)$ and $\mathrm{V}(B)$, were performed, then $R_{\mathrm{ST}}$ was calculated for each bootstrap replicate. The $R_{\mathrm{ST}}$ values were ranked in ascending order, and the 25th-lowest and 24th-highest values defined the 95 per cent confidence interval. Associations between geographical distance and values of either $\theta$ or $R_{\mathrm{ST}}$ for pairs of samples were tested for significance by performing two-matrix Mantel tests using the R package (1000 permutations, Legendre \& Vaudor, 1991).

The method of Waples (1989) was used to estimate effective population size $\left(N_{\mathrm{e}}\right)$ within a sample site. This method provides an estimate of variance $N_{\mathrm{e}}$ based on the variance in allele frequency over a few generations. The data consist of the allele frequencies in two samples taken at different times from the same site, and it is assumed that the only source of variance in allele frequency is genetic drift. It was assumed that sampling occurred before reproduction, and that house mice have two generations per year.

\section{Results}

Genotypic proportions of microsatellites and $\mathrm{Rb}$ chromosomes within samples were compared with Hardy-Weinberg expectations using Fisher's exact 
tests (data not shown). The high levels of withinsample polymorphism (heterozygosity of $0.44-0.70$, average of eight microsatellite loci) made most markers informative. Heterozygote deficit was observed in two out of 91 tests for microsatellites, and in two out of 11 tests for the Rb chromosomes (for $\mathrm{Rb}(4.12)$ in the La Hulpe samples LH1 and LH2, see Bauchau et al., 1990) after sequential Bonferroni correction $(\alpha=0.05, K=10$, independent tests, Rice, 1989). The virtual lack of heterozygote deficit for microsatellites suggests that null alleles are absent or at low frequency. Overall, mating in the study populations appears to occur mostly at random: both inbreeding and further subdivision are absent.

Levels of genetic subdivision over the study area were estimated using seven samples from different sites (microsatellite data only). Two statistics, $\theta$ and $R_{\mathrm{ST}}$, were calculated as single-locus values and as multilocus averages. Table 1 shows the values of $F, \theta$ and $f$, which are estimators of Wright's $F_{\mathrm{IS}}, F_{\mathrm{ST}}$ and $F_{\text {IT }}$, respectively (Weir \& Cockerham, 1984), and $R_{\mathrm{ST}}$ (Slatkin, 1995). These samples give significant and virtually identical multilocus values of $\theta$ and $R_{\mathrm{ST}}$. The single-locus values of $R_{\mathrm{ST}}$ are more variable than those of $\theta$, so $R_{\mathrm{ST}}$ has wider confidence intervals generated by bootstrapping over loci. This is not surprising as $R_{\mathrm{ST}}$ contains information on both allele size and frequency, whereas $\theta$ contains only allele frequency information. Bootstrapping over different numbers of loci suggested that to arrive at equal confidence intervals for both statistics twice as many loci would be required for $R_{\mathrm{ST}}$ as for $\theta$. Consistent

Table 1 Spatial genetic subdivision in Belgian house mice

\begin{tabular}{lccrc}
\hline Locus & $F$ & $\theta$ & \multicolumn{1}{c}{$f$} & $R_{\mathrm{ST}}$ \\
\hline 34 & 0.33 & 0.32 & 0.01 & 0.25 \\
105 & 0.23 & 0.23 & -0.01 & 0.10 \\
135 & 0.23 & 0.24 & 0.00 & 0.42 \\
150 & 0.18 & 0.19 & -0.01 & 0.11 \\
D7Mit18 & 0.36 & 0.40 & -0.06 & 0.35 \\
D11Mit16 & 0.40 & 0.38 & 0.03 & 0.30 \\
D13Mit14 & 0.30 & 0.28 & 0.03 & 0.39 \\
D15Mit16 & 0.38 & 0.29 & 0.13 & 0.34 \\
Average & 0.30 & 0.29 & 0.02 & 0.27 \\
95\% CI & $0.25-0.35$ & $0.24-0.34$ & $0.02-0.05$ & $0.18-0.35$ \\
\hline
\end{tabular}

Samples analysed were LH6, CHA, MON, COR, SNa, $\mathrm{SNb}$ and SPA.

$F, \theta$ and $f$ are estimators of Wright's $F_{\mathrm{IT}}, F_{\mathrm{ST}}$ and $F_{\mathrm{IS}}$, respectively.

CI: confidence interval based on 1000 bootstrap resamples of single-locus values.

(c) The Genetical Society of Great Britain, Heredity, 80, 70-77. with the Hardy-Weinberg test results, the mean $f$-value is not significantly different from zero. Table 2 shows that the $\theta$ value for the seven Belgian samples of $M . m$. domesticus is significantly higher than those for both four M. m. domesticus samples and seven M. m. musculus samples from either side of the hybrid zone in Eastern Jutland (Dallas et al., 1995). This result is not an artefact of confounding different sets of markers or different scales of geographical distance in the two studies, or of genetic differentiation between standard and $\mathrm{Rb}$ populations in Belgium.

The relationship between genetic subdivision and geographical distance was examined. Figure $2 a$ and $b$ shows pairwise multilocus values of $\theta$ and $R_{\mathrm{ST}}$, respectively, plotted against straight-line distance between sites. Values corresponding to 40-40, $40-R b$, and $R b-R b$ pairs of samples are given different symbols. Most pairwise $\theta$ and $R_{\mathrm{ST}}$ values are large, including those for the closest pair of sites, Spontin a and b, which are adjacent houses about $300 \mathrm{~m}$ apart. Mantel tests showed that no significant association exists between distance and either $\theta$ or $R_{\mathrm{ST}}$ over the geographical scale studied $(P>0.2$ or 0.36 , respectively). This not surprising given the high scatter of pairwise values of both statistics in these samples: $0.18-0.39$ for $\theta$, and $0.07-0.49$ for $R_{\mathrm{ST}}$. As above, $R_{\mathrm{ST}}$ values show more variability than $\theta$ values. There is no obvious effect of karyotype on levels of subdivision: the $\theta$ and $R_{\mathrm{ST}}$ values for the $40-40,40-R b$, and $R b-R b$ pairs of samples appear to be scattered randomly over the whole ranges.

Temporal stability in genetic composition at one site in the $\mathrm{Rb}$ race, La Hulpe, was assessed over a period of 3 years. Values of $\theta$ between pairs of samples were calculated for both successive (LH1 vs. LH2, LH2 vs. LH3, etc.) and cumulative (LH1 vs. LH2, LH1 vs. LH3, etc.) time intervals. Correlations between length of time interval and $\theta$ were tested for significance using the Mantel test. $R_{\mathrm{ST}}$ was not used here because the timescale was considered too short for mutation to be relevant. All the successive $(\theta=0.03-0.12)$ and cumulative $(\theta=0.10-0.14)$ intervals gave significant values (Fig. 3). There was no correlation between $\theta$ and interval length in either case (data not shown). These results show that significant temporal changes in genetic composition occurred at La Hulpe in each of the five intervals between sampling, two of which were as short as 3.6 months. However, the degree of change did not increase over longer intervals. The temporal changes in microsatellite allele frequencies at La Hulpe were used to calculate corresponding values of variance $N_{\mathrm{e}}$ (Table 3), using the method of Waples (1989). 
Table 2 Genetic subdivision in house mice from three European locations

\begin{tabular}{llccccc}
\hline & & Loci $^{\mathrm{c}}$ & Samples & Distance $(\mathrm{km})$ & $\theta$ & 95\% CI \\
\hline M. m. domesticus & Belgium $^{\mathrm{a}}$ & 8 & 7 & $0.5-59$ & 0.29 & $0.24-0.34$ \\
M. $m$. domesticus & E. Jutland $^{\mathrm{b}}$ & 6 & 4 & $6-22$ & 0.18 & $0.12-0.22$ \\
M. m. musculus & E. Jutland $^{\mathrm{b}}$ & 5 & 7 & $0.5-120$ & 0.14 & $0.10-0.17$ \\
\hline
\end{tabular}

${ }^{\text {a }}$ This study; ${ }^{b}$ Dallas et al., 1995; ' five out of the six microsatellite loci used in the Jutland domesticus, and all five of those used in the Jutland musculus, are a subset of those used in this study.
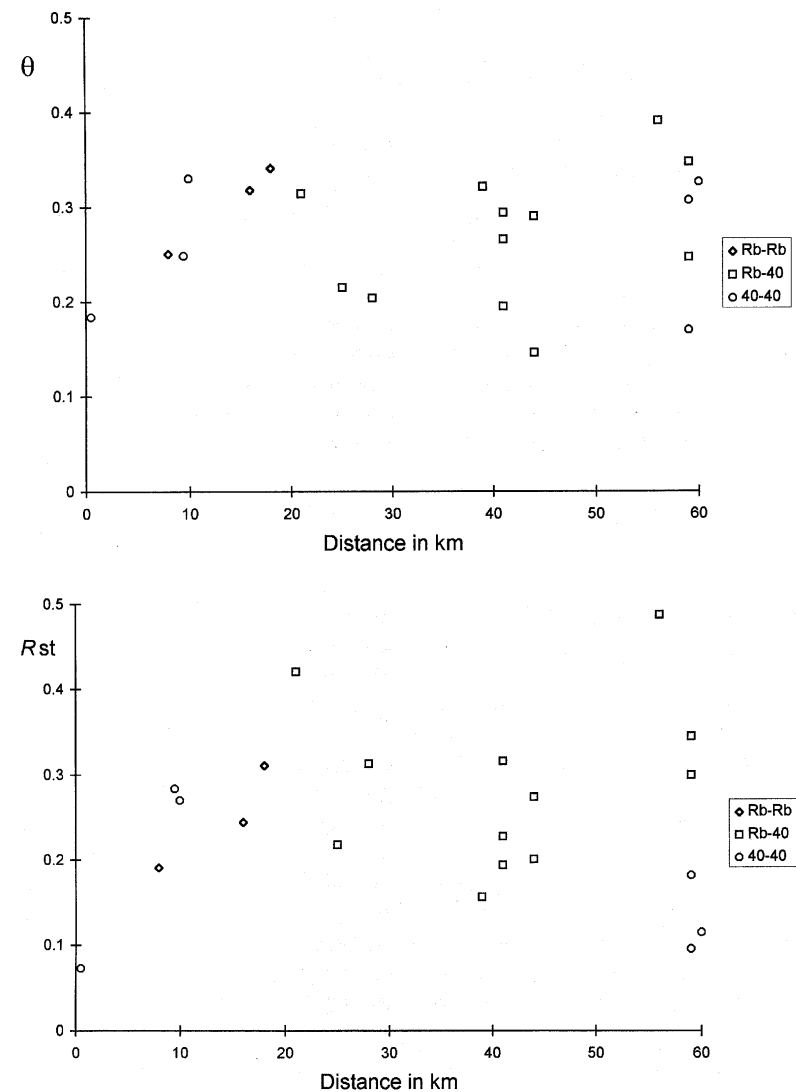

Fig. 2 Values of (a) $\theta$, and (b) $R_{\mathrm{ST}}$, for pairs of samples of house mice plotted against distance between sample sites (microsatellite data only).
All $N_{\mathrm{e}}$ values are much smaller than most of the samples obtained at this site, suggesting that the variance $N_{\mathrm{e}}$ of the La Hulpe population is a fraction of the likely census size.

Cases of within-sample two-locus disequilibrium among all possible pairs of microsatellite and $\mathrm{Rb}$ markers were identified using Fisher's exact tests followed by sequential Bonferroni correction ( $\alpha=0.05, K=28,36$ or 45 , nonindependent tests). Not all pairs of loci could be tested because $\mathrm{Rb}(4.12)$ and/or $\mathrm{Rb}(5.10)$ were monomorphic in some samples, and because $\mathrm{Rb}(5.10)$ had not been scored in the last four samples. Overall, 19 out of 402 significant cases were identified (Table 4). These were strongly clustered by locus pair and sample:

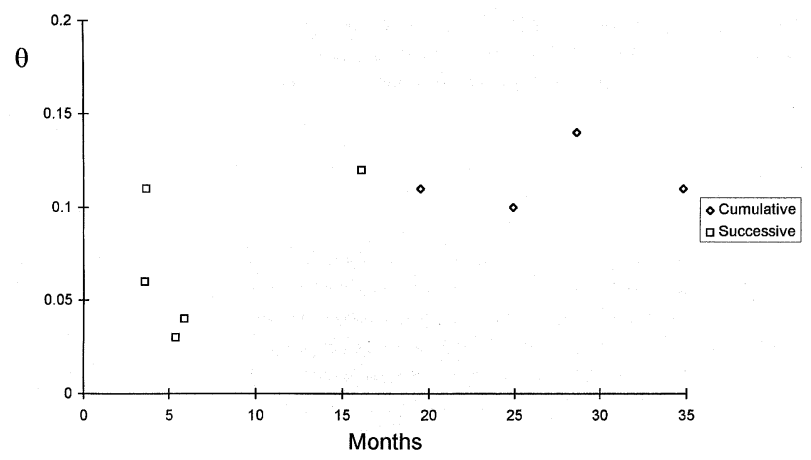

Fig. 3 Values of $\theta$ for pairs of La Hulpe samples of house mice plotted against time intervals between sampling. Successive and cumulative time intervals were analysed (microsatellite data only).

Table 3 Variance-effective population sizes of house mice at La Hulpe

\begin{tabular}{llllll}
\hline $\begin{array}{l}\text { Interval } \\
\text { Months }^{\mathrm{a}}\end{array}$ & $\begin{array}{l}\text { LH1-6 } \\
35\end{array}$ & $\begin{array}{l}\text { LH1-2 } \\
16\end{array}$ & $\begin{array}{l}\text { LH2-3 } \\
4\end{array}$ & $\begin{array}{l}\text { LH3-5 } \\
8\end{array}$ & $\begin{array}{l}\text { LH5-6 } \\
7\end{array}$ \\
\hline$N_{\mathrm{e}}^{\mathrm{b}}$ & 19.5 & 10.6 & 5.3 & 5.5 & 7.3 \\
$95 \%$ CI & $9.7-34.8$ & $5.3-18.8$ & $2.4-10.4$ & $2.4-11.2$ & $3.0-19.3$ \\
\hline
\end{tabular}

${ }^{\mathrm{a}}$ Generation time was assumed to be 6 months (Boursot et al., 1993). ${ }^{\mathrm{b}} N_{\mathrm{e}}$ and the $95 \%$ confidence intervals were calculated using equations 11 and 15 , respectively, in Waples (1989). 
Table 4 Cases of two-locus disequilibrium within samples of house mice

\begin{tabular}{llll}
\hline Sample & $K$ & Cases & Locus pairs (cM) \\
\hline LH1 & 36 & 1 & $34-135(15)$ \\
LH2 & 36 & 2 & $34-135(15), 34-D 15 M i t 16(U L)$ \\
LH3 & 28 & 2 & $34-135(15), 34-150($ UL) \\
LH4 & 28 & None & \\
LH5 & 45 & None & \\
LH6 & 45 & 1 & $34-135(15)$ \\
CHA & 36 & None & \\
MON & 36 & None & \\
COR & 28 & 11 & $105-D 7 M i t 18(29)$ and 10 UL loci \\
SNa & 28 & None & \\
SNb & 28 & 2 & $34-135(15), 105-D 7 M i t 18(29)$ \\
SP & 28 & None & \\
\hline
\end{tabular}

$K$, number of locus pairs which could be tested; UL, unlinked loci.

seven cases involved the two pairs of linked loci 34-135 (15 cM) and 105-D7Mit18 (29 cM), and 11 cases involved the Corroy sample.

\section{Discussion}

These results show that the genetic structure of house mice in central Belgium is strongly perturbed by population-level factors: between-population genetic subdivision was marked, genetic composition in one population was temporally unstable, and two-locus disequilibria between loosely or unlinked loci were detected. Two factors could be responsible for the subdivision: (i) genetic drift caused by local populations being isolated and having small effective sizes; and (ii) extinction-recolonization events, in which colonizers have a high probability of originating from the same source population (Whitlock \& McCauley, 1990). Both factors could operate in combination in house mice. Although this makes their influence difficult to separate in the present study, it is important to note that both factors can promote the fixation of underdominant $\mathrm{Rb}$ chromosomes (see Introduction). The study populations do not appear to be influenced by either inbreeding or further subdivision. Similar results have been found in other M. m. domesticus populations from Europe, the Middle East and North Africa (Britton-Davidian, 1990; Dallas et al., 1995). Thus, inbreeding is unlikely to slow down the fixation of underdominant $\mathrm{Rb}$ chromosomes in M. m. domesticus populations (Hedrick, 1981).

The demonstration of random mating conflicts with the view that commensal house mice are subdivided into reproductive units or demes of a few males and several females (Boursot et al., 1993). Although demic structure was not studied directly here, there is nothing to suggest that the Belgian populations were atypical in this respect. On the other hand, absence of homozygote excess is consistent with inbreeding avoidance. There is evidence for inbreeding depression in house mice: disassortative mating for MHC alleles may be one mechanism for its avoidance (Potts et al., 1994). The results of the present study imply that a high proportion of matings and/or recruitment in commensal house mice occurs between demes. Such interdeme exchanges may extend far enough to promote high levels of localized gene flow in commensal house mice. Gene flow in commensal house mice does occur at a very local scale (Baker, 1981).

The average level of subdivision in M. m. domesticus in central Belgium was significantly higher than that found in M. m. domesticus and M. m. musculus from Jutland (Dallas et al., 1995). The former populations contain $\mathrm{Rb}$ polymorphism (Nance et al., 1990), whereas the latter form displays very little $\mathrm{Rb}$ polymorphism throughout its whole range (Zima et al., 1990). This comparison suggests that subdivision may contribute to maintaining $\mathrm{Rb}$ polymorphism in at least some populations of M. m. domesticus. As well as in the present study, the influence of genetic drift on an $\mathrm{Rb}$ population on the Island of Faray, Orkney, has been clearly demonstrated (Berry et al., 1992). The Jutland populations of M. m. musculus may be atypically more subdivided than elsewhere because they are seasonally commensal (Carlsen, 1993). Local population genetic structure, especially concerning dispersal among adjacent populations, needs to be further characterized in both forms of house mice.

The changes in the genetic composition of the La Hulpe population observed over the 3-year study period exemplify the kind of stochastic perturbations which may be common in the study populations. Although it is true that mice were removed in sampling this site, perhaps inflating the variance in allele frequencies, the La Hulpe population must have been small to begin with for sampling to have had such an effect. Moreover, the interval between the first and second samples (16 months, $N_{\mathrm{e}}=10.6$ ), was sufficiently long for the population size to have recovered. Such temporal genetic instability was also found in three commensal populations of $M . \mathrm{m}$. domesticus and M. m. musculus in Jutland. In that study the intervals between sampling were sufficiently long to allow population recovery (1-7 years, Dallas et al., 1995). Temporal fluctuations in genetic 
composition may, therefore, be characteristic of populations of commensal house mice. Demographic instability is a potential mechanism causing genetic drift in house mice: marked and released individuals typically have a monthly recapture rate lower than 50 per cent (Baker, 1981).

It is not surprising that the study populations display significant two-locus disequilibria more frequently than Hardy-Weinberg disequilibria. If a population perturbation creates both types of disequilibria simultaneously in a finite population, subsequent random mating will cause Hardy-Weinberg disequilibria to vanish rapidly, whereas two-locus disequilibria will be merely reduced by a factor $1-r-1 /(2 N)$ each generation. Genetic drift can create disequilibria when the product of population size $(N)$ and recombination rate $(r)$ is sufficiently small, that is when $4 N r<10$ (Hartl \& Clarke, 1989). The $N_{\mathrm{e}}$ estimates for La Hulpe (5-20) are consistent with finding the most closely linked pair of microsatellite loci (34 and 135, $r=0.15$ ) in significant disequilibrium in four La Hulpe samples (because $4 N r=3-12$ ). A recent recolonization event may explain why 10 pairs of nonsyntenic loci $(r=0.5)$ are in disequilibrium in the Corroy population.

Gene flow appears insufficient to eliminate subdivision at any geographical scale studied here. The two practically adjacent sites (Spontin a and b) are significantly differentiated. In order to learn how gene flow in house mice occurs, further ecological and genetic data on dispersal among such adjacent populations are needed. Gene flow can have a strong influence in maintaining levels of polymorphism in the overall population despite marked transient genetic subdivision created by drift (Nürnberger \& Harrison, 1995). The lack of geographical association in the pattern of genetic subdivision tends to favour an island-type migration model over a stepping-stone type, at least over the range of distances studied here $(8-60 \mathrm{~km}$, ignoring the closest pair of populations). Thus, passive transport via the movement of agricultural materials may be the dominant means of dispersal over this scale of distance. The large spread of pairwise values observed for $\theta$ and $R_{\mathrm{ST}}$ is probably not compatible with a state of migration-drift equilibrium, so the numbers of migrants were not calculated. Nonetheless, some immigration of mice carrying novel alleles has probably influenced all the study populations because their observed levels of heterozygosity are much higher than those predicted at mutation-drift equilibrium by the variance $N_{\mathrm{e}}$ values for the $\mathrm{La}$ Hulpe population (Dallas et al., 1995).
The finding that Robertsonian races have originated independently in different areas of Europe (Nachman et al., 1994) suggests that biological traits of house mice as a whole, or the meiotic drive of individual $\mathrm{Rb}$ chromosomes, are responsible for such polymorphism, not any lineage-specific factors. Whatever factors are ultimately responsible for the origin of $\mathrm{Rb}$ races in house mice (Nachman \& Searle, 1995), this study suggests that the $\mathrm{Rb}$ race in central Belgium is influenced by population-level factors theoretically capable of promoting the fixation of underdominant mutations.

\section{Acknow ledgements}

We thank J.-C. Auffray, J. Catalan, H. Croset, D. Nootens, S. Smets and M.-C. Viroux for collecting and karyotyping mice, P. Bacon, K. Belkhir, D. Elston, J. Goudet and M. Raymond for help with computer programs, and G. Ganem and M. Slatkin for useful comments. This work was supported by postdoctoral grants from the French government (to J. D.) and the FNRS (to V. B.), by EEC research contracts S.C.I. 0272 (to F. B.) and BIO2 CT920476 (to P. B.), and by funds from CNRS-ATP and UMII-BEE (to J. B.-D.).

\section{References}

BAKER, A. E. M. 1981. Gene flow in house mice: introduction of a new allele into free-living populations. Evolution, 35, 243-258.

BARTON, N. H. AND ROUHANI, s. 1991. The probability of fixation of a new karyotype in a continuous population. Evolution, 45, 499-517.

BAUCHAU, V., SMETS, S., VIROUX, M-C., NOOTENS, D. AND DE CARITAT, A.-K. 1990. Robertsonian translocations in free-living populations of the house mouse in Belgium. Biol. J. Linn. Soc., 41, 193-201.

BERRY, R. J., BERRY, A. J., ANDERSON, T. J. C. AND SCRIVEN, P. 1992. The house mice of Faray, Orkney. J. Zool., 228, 233-246.

BOURSOT, P., AUFFRAY, J.-C., BRITTON-DAVIDIAN, J. AND Bonhomme, f. 1993. The evolution of house mice. Ann. Rev. Ecol. Syst., 24, 119-152.

BRITTON-DAVIDIAN, J. 1990. Genic differentiation in M. m. domesticus populations from Europe, the Middle East, and North Africa: geographical patterns and colonization events. Biol. J. Linn. Soc., 41, 27-45.

CARLSEN, M. 1993. Migrations of Mus musculus musculus in Danish farmland. Z. Säugetierk., 58, 172-180.

DALLAS, J. F., DOD, B., BOURSOT, P., PRAGER, E. M. AND BONHOMME, F. 1995. Population subdivision and gene flow in Danish house mice. Mol. Ecol., 4, 311-320.

DIETRICH, W., KATZ, H., LINCOLN, S. E., SHIN, H.-S., FRIEDMAN, J., DRACOPOLI, N. C. AND LANDER, E. S. 1992. A

(C) The Genetical Society of Great Britain, Heredity, 80, 70-77. 
genetic map of the mouse suitable for typing intraspecific crosses. Genetics, 131, 423-447.

DIRIENZO, A., PETERSON, A. C., GARZA, J. C., VALDES, A. M., SLATKIN, M. AND FREIMER, N. B. 1994. Mutational processes of simple-sequence repeat loci in human populations. Proc. Natl. Acad. Sci. U.S.A., 91, 3166-3170.

EVANS, E. P. 1987. Karyotyping and sexing of gametes, embryos and fetuses and in situ hybridization to chromosomes. In: Monks, M. (ed.) Mammalian Development: A Practical Approach, pp. 93-114. I.R.L. Press, Oxford.

GROPP, A. AND WINKING, H. 1981. Robertsonian translocation, cytology, meiosis, segregation patterns and biological consequences of heterozygosity. Symp. Zool. Soc. Lond., 47, 141-181.

Hartl, D. L. AND Clark, A. G. 1989. Principles of Population Genetics, 2nd edn. Sinauer Associates, Sunderland, MA.

HAUfFE, H. C. AND SEARLE, J.B. 1993. Extreme karyotypic variation in a Mus musculus domesticus hybrid zone. The tobacco mouse story revisited. Evolution, 47, 1374-1395.

HEARNE, C. M., MCALEER, M. A., LOVE, J. M., AITMAN, T. J., CORNALL, R. J., GHOSH, S. ET AL. 1991. Additional microsatellite markers for mouse genome mapping. Mamm. Gen., 1, 273-282.

HEDRICK, P. W. 1981. The establishment of chromosomal variants. Evolution, 35, 322-332.

LANDE, R. 1985. The fixation of chromosomal rearrangements in a subdivided population with local extinction and colonisation. Heredity, 54, 323-332.

LEGENDRE, P. AND VAUDOR, A. 1991. The $R$ package, multidimensional analysis, spatial analysis. Département de Sciences Biologiques, Université de Montréal.

MICHALAKIS, Y. AND EXCOFFIER, L. 1996. A generic estimation of population subdivision using distances between alleles with special reference for microsatellite loci. Genetics, 142, 1061-1064.

MICHALAKIS, Y. AND OLIVIERI, I. 1993. The influence of local extinctions on the probability of fixation of chromosomal rearrangements. J. Evol. Biol., 6, 153-170.

NACHMAN, M. W. AND SEARLE, J.B. 1995. Why is the house mouse karyotype so variable? Trends Ecol. Evol., 10, 397-402.
NACHMAN, M. W., BOYER, S. N., SEARLE, J. B. AND AQUADRO, C. F. 1994. Mitochondrial DNA variation and the evolution of Robertsonian chromosomal races of house mice, Mus domesticus. Genetics, 136, 1105-1120.

NANCE, V., VANLERBERGHE, F., NIELSEN, J. T., BONHOMME, F. AND BRITTON-DAVIDIAN, J. 1990. Chromosomal introgression in house mice from the hybrid zone between Mus musculus domesticus and M. m. musculus in Denmark. Biol. J. Linn. Soc., 41, 215-227.

NÜRNBERGER, B. AND HARRISON, R. G. 1995. Spatial population structure in the whirligig beetle Dineutus assimilis: evolutionary inferences based on mitochondrial DNA and field data. Evolution, 49, 266-275.

POTTS, W. K., MANNING, C. J. AND WAKELAND, E. K. 1994. The role of infectious disease, inbreeding and mating preferences in maintaining MHC genetic diversity: an experimental test. Phil. Trans. R. Soc. B, 346, 369-378.

RAYMOND, M. AND ROUSSET, F. 1995. GENEPOP (ver. 1.2), a population genetics software for exact tests and ecumenicism. J. Hered., 86, 248-249.

RICE, W. R. 1989. Analyzing tables of statistical tests. Evolution, 43, 223-225.

SLATKIN, M. 1995. A measure of population subdivision based on microsatellite allele frequencies. Genetics, 139, 457-462.

WAPLES, R. S. 1989. A generalised approach for estimating effective population size from temporal changes in allele frequency. Genetics, 121, 379-391.

WEIR, B. s. 1990. Intraspecific differentiation. In: Hillis, D. M. and Moritz, C. (eds) Molecular Systematics, pp. 373-410. Sinauer Associates, Sunderland, MA.

WEIR, B. S. AND COCKERHAM, C. C. 1984. Estimating $F$-statistics for the analysis of population structure. Evolution, 38, 1358-1370.

WHITLOCK, M. C. AND McCAUlEy, D. E. 1990. Some population genetic consequences of colony formation and extinction: genetic correlations within founding groups. Evolution, 44, 1717-1724.

WRIGHT, s. 1941 . On the probability of fixation of reciprocal translocations. Am. Nat., 74, 513-522.

ZIMA, J., GAICHENKO, v. A., MACHOLAN, M., RADJABLI, S. I., SABLINA, O. V. AND WOJCIK, J. M. 1990. Are Robertsonian variations a frequent phenomenon in mouse populations in Eurasia. Biol. J. Linn. Soc., 41, 229-233. 